\title{
Cutaneous squamous cell carcinoma metastatic to parotid - analysis of prognostic factors and treatment outcome
}

\author{
Robin Yeong Hong Goh', Ron Bova ${ }^{1,2}$ and Gerald B Fogarty ${ }^{1,3,4^{*}}$
}

\begin{abstract}
Background: Cutaneous squamous cell carcinoma (CSCC) comprises $20 \%$ of all skin cancer of the head and neck. A minority will metastasize to regional parotid lymph nodes. This study evaluates the St Vincent's Hospital, Sydney experience between 1996 and 2006.

Methods: A retrospective review was performed of patients who were evaluated in our multidisciplinary head and neck clinic with metastatic CSCC to parotid, and all treatment and pathologic details were reviewed. Statistical analysis, including univariate and multivariate analyses, were performed using Cox proportional hazards regression mode, overall and disease-specific survival were estimated by the Kaplan-Meier method.

Results: Sixty-seven patients were identified. Some $90 \%$ were male, and with a mean age of 72.8 years. One died on the first postoperative day. The remaining 66 patients received radiotherapy. For these 66 patients, the two-year and five-year overall survival rate was 0.83 and 0.72 , respectively. The two-year and five-year disease-free survival rate was 0.91 and 0.83 respectively. Overall survival was only significantly correlated to the extent of parotidectomy (superficial versus total; $P=0.0256$ ). Margin status was available in 59 patients. The only parameter that significantly correlated with disease-free survival was margin status (close/negative versus positive $P=0.0348$ ). Other parameters of immune suppression, perineural invasion, extra capsular extension, degree of tumour differentiation, number of positive nodes, extent of neck dissection and radiotherapy dosage delivered did not confer prognostic significance.
\end{abstract}

Conclusions: This study confirmed the association of adverse prognostic implication of positive margins on disease-free survival. Immune compromise was not a significant factor in this small group. Further studies are warranted in this population.

Keywords: Audit, Head and neck, Immune suppression, Metastasis, Neck lymph nodes, Parotidectomy, Radiotherapy, Skin cancer

\section{Background}

The most common malignancy in the human person is skin cancer. [1]. Australia has the highest incidence of skin cancer in the world [2]. Cutaneous squamous cell carcinoma (cSCC) incidence in Australia is rising. From 1985 to 2002, age-standardised incidence rates of cSCC had increased by $133 \%$ [2]. The mortality is also increasing [3]. Some $20 \%$ of all skin cancer of the head and neck are

\footnotetext{
* Correspondence: gerald.fogarty@cancer.com.au

${ }^{1}$ Faculty of Medicine, University of New South Wales, Botany Street, Sydney, NSW 2052, Australia

${ }^{3}$ Genesis Cancer Care, St Vincent's Clinic, 438 Victoria Street, Darlinghurst, NSW 2010, Australia

Full list of author information is available at the end of the article
}

cSCC [4]. Only a minority of facial and scalp cSCC will metastasise to regional parotid lymph nodes. It is an Australian phenomenon that the most common malignant tumour of the parotid gland is metastatic cSCC [5]. These patients suffer increased morbidity and even mortality if locoregional control is not achieved at first presentation

Definitive treatment of metastatic cSCC to the parotid is a therapeutic challenge requiring multidisciplinary input and multimodality therapy. The purpose of this study was to evaluate our experience in treating metastatic CSCC to the parotid gland in patients presenting to our multidisciplinary head and neck clinic.

Our institutional management policy for this disease is as follows. Parotidectomy with appropriate neck dissection

\section{Biomed Central}


is considered the standard of care for patients with metastatic cutaneous SCC to the parotid gland in our institution. The extent of parotidectomy is based on preoperative clinical and radiologic assessment and follows the definitions of neck dissection defined by Robbins et al. [6]. Superficial parotidectomy with facial nerve conservation is appropriate for the majority of patients unless facial nerve infiltration is identified preoperatively or tumour infiltration into the facial nerve is identified at the time of surgery, in which case, total parotidectomy with facial nerve resection is considered. Similarly, if adjacent soft tissue structures such as preauricular skin or external auditory canal are involved clinically or radiologically, then extended resection encompassing the surrounding soft tissues with appropriate local or flap reconstruction is considered. Adjuvant radiotherapy to the parotid bed and ipsilateral neck starting within six weeks of operation is then given. The surgical bed is planned for treatment to 60 to $66 \mathrm{~Gy}$, the neck to 45 to $56 \mathrm{~Gy}$, all in 1.8 to 2 Gy fractions at five fractions per week. Treatment is discontinued if there is significant radiation toxicity. Concurrent chemotherapy was not used routinely in this patient population at this time.

\section{Methods}

A retrospective review of patients with metastatic cSCC to the parotid gland who were treated with curative intent at St. Vincent's Hospital during a 10-year period (1996 to 2006) was performed. Research was carried out in compliance with the Helsinki Declaration and this project was approved by the St Vincent's Hospital Human Research Ethics Committee approval number $08 / 108$. All patients were evaluated in a multidisciplinary head and neck clinic and all clinical and pathological data was prospectively recorded. Data collected included: age, sex, immune status, primary skin tumour site if available, nodal involvement, margin status, extracapsular extension, perineural invasion, extent of surgery performed and radiotherapy details. Immune-compromised patients included patients with intercurrent haematological malignancies, lymphoma and transplant recipients on long-term immunosuppressive treatment.

Statistical analysis was performed using STATA version 9 (Stata Corp., College Station, TX, USA). Univariate and multivariate analyses were performed using Cox proportional hazards regression mode and overall survival (OS) and disease-specific survival (DSS) were estimated by the Kaplan-Meier method. The OS period was calculated from parotidectomy to date of death or last follow-up. The DSS period was calculated from parotidectomy to date of death from disease or last follow-up.

Multivariate analysis of factors influencing OS and DSS were performed on selected explanatory variables by means of a Cox's proportional hazards regression. A step-wise approach was used to select independent significant covariates. The variables were analysed via a nominal categorization. The probabilities of entry and removal from the multivariate model were set at 0.10 and 0.10 , respectively. Prognostic factors that showed significant $P$ value of less than 0.1 in univariate analysis were investigated in the multivariate analyses. These were immune suppression, margin status of parotid, parotidectomy and O’Brien P stage [5].

\section{Results}

\section{Patient characteristics}

Sixty-seven patients that fulfilled the eligibility criteria for this study and their details are summarised in Table 1. Some $90 \%$ of the patients were male and the mean age of the patients was 72.8 years. Forty-one (61\%) patients presented with metastatic cSCC to the parotid only while 26 (39\%) patients presented with metastatic cSCC to both parotid and ipsilateral cervical lymph nodes. Eight patients (12\%) were immune-compromised at the time of surgery. Three patients had non-Hodgkin's lymphoma and five patients had chronic lymphocytic leukemia. Eleven patients had a history of primary lesion that was thought responsible for the parotid nodes.

\section{Treatment characteristics}

All patients underwent parotidectomy. Fifty-three patients had superficial parotidectomy performed while fourteen patients underwent total parotidectomy. Fifty-four patients had an ipsilateral neck dissection performed. Of these twenty-eight had radical neck dissection, thirteen had modified radical neck dissection, twelve had selective neck dissection and one patient had an extended radical neck dissection.

One patient died on the first postoperative day. This patient was excluded from the survival analysis. The remaining sixty-six patients all received planned postoperative

\section{Table 1 Patient characteristics}

\begin{tabular}{llll}
\hline & All & $\begin{array}{l}\text { Patients with } \\
\text { cancer spread } \\
\text { to parotid only }\end{array}$ & $\begin{array}{l}\text { Patients with } \\
\text { cancer spread } \\
\text { to parotid } \\
\text { and neck }\end{array}$ \\
\hline $\mathrm{N}$ & 67 & $41(61.2 \%)$ & $26(38.8 \%)$ \\
\hline Sex & & $21(4.9 \%)$ & $5(19.2 \%)$ \\
\hline Female & $7(10.4 \%)$ & $21(80.8 \%)$ \\
\hline Male & $60(89.6 \%)$ & $39(95.1 \%)$ & $72.7 \pm 12.0$ \\
\hline $\begin{array}{l}\text { Age in years } \\
\text { (mean } \pm \text { SD) }\end{array}$ & $72.8 \pm 11.5$ & $72.9 \pm 11.4$ & \\
\hline Immunosuppression & & & $3(12.0 \%)$ \\
\hline Immune-compromised & $8(12.1 \%)$ & $5(12.2 \%)$ & $22(88.0 \%)$ \\
\hline $\begin{array}{l}\text { Non-immune- } \\
\text { compromised }\end{array}$ & $58(87.9 \%)$ & $36(87.8 \%)$ & \\
\hline
\end{tabular}


adjuvant radiotherapy. All 66 patients received radiotherapy to the parotid bed, and 65 to the ipsilateral neck. The average dose of radiotherapy to the parotid and upper neck was 53.9 Gy (SD: $5.6 \mathrm{~Gy}$ ), while the lower neck received an average dose of 43.6 Gy (SD: 19.8 Gy). Three received platinum-based concurrent chemotherapy.

\section{Pathologic characteristics}

Sixty patients had a complete histopathology report from the parotidectomy available for analysis. The average number of parotid lymph nodes removed was 4.5 while the average number of positive parotid nodes removed was 1.7. The largest parotid node removed was $7 \mathrm{~cm}$ with $50 \%$ of positive nodes measuring greater than $2 \mathrm{~cm}$. Nine patients (15\%) had histological evidence of perineural invasion while thirty-five (57\%) patients displayed extra capsular extension in the parotidectomy specimen.

Parotidectomy specimens were also assessed for margin status. Margin status was available in 59 patients and was classified as positive, negative or close (if $<0.5 \mathrm{~mm}$ ). Twenty-one patients (35\%) had positive margins, twentythree $(38 \%)$ were negative and fifteen patients $(25 \%)$ had close margins.

\section{Overall survival outcomes and associations}

For the 66 patients, the two-year and five-year overall survival rate was 0.83 and 0.72 , respectively. (See Figure 1, Additional file 1). Overall survival was only significantly correlated with the extent of parotidectomy (superficial versus total; $P=0.0256$ ). Patients that required total parotidectomy had reduced survival compared to those that had superficial parotidectomy performed (See Figure 2). O'Brien staging [5] for overall survival was almost significant for $\mathrm{P} 1$ versus $\mathrm{P} 2+\mathrm{P} 3 \quad(P=0.0531)$.

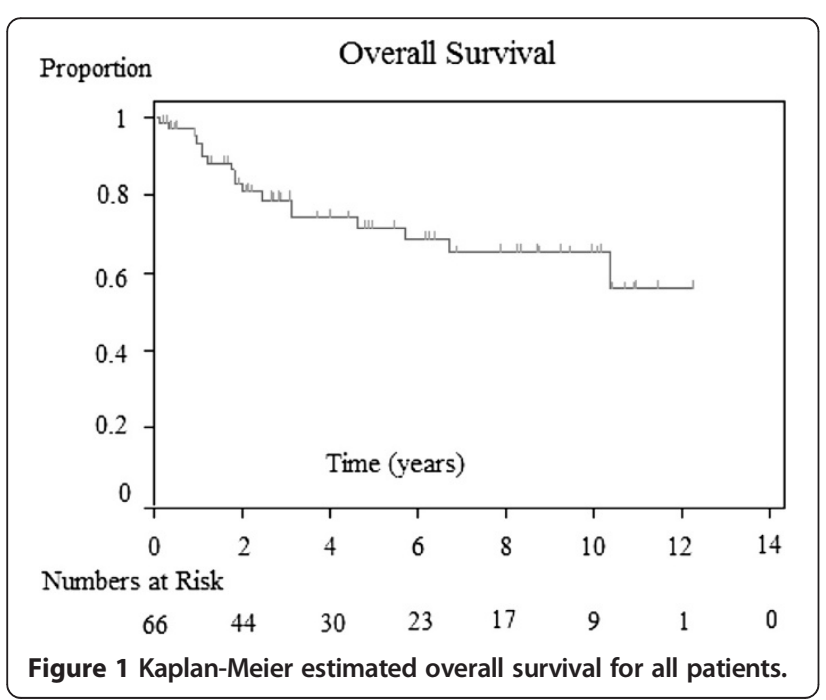

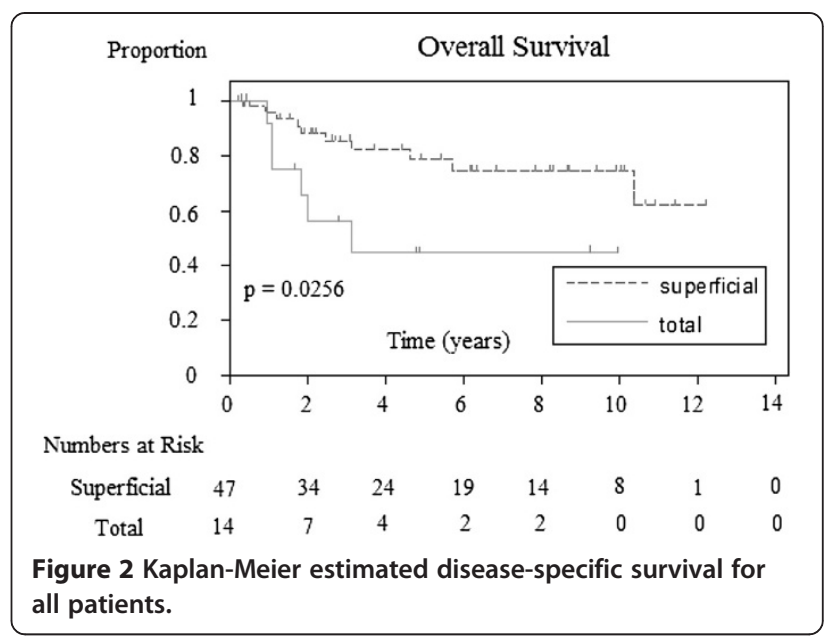

Parameters of immune suppression, perineural invasion, extracapsular extension, degree of tumour differentiation, number of positive nodes, extent of neck dissection and radiotherapy dosage delivered did not confer prognostic significance.

\section{Disease-specific survival outcomes and associations}

The two-year and five-year disease-free survival rate was 0.91 and 0.83 respectively. (See Figure 3, Additional file 2). The only parameter that significantly correlated with disease-free survival was margin status (Close/ negative versus positive $P=0.0348$ ). Patients with close or negative margins had improved two-year and five-year survival compared to patients with positive margins (See Figure 4). Parameters of immune suppression, perineural invasion, extracapsular extension, degree of tumour differentiation, number of positive nodes, O'Brien staging, extent of neck dissection and radiotherapy dosage delivered did not confer prognostic significance.

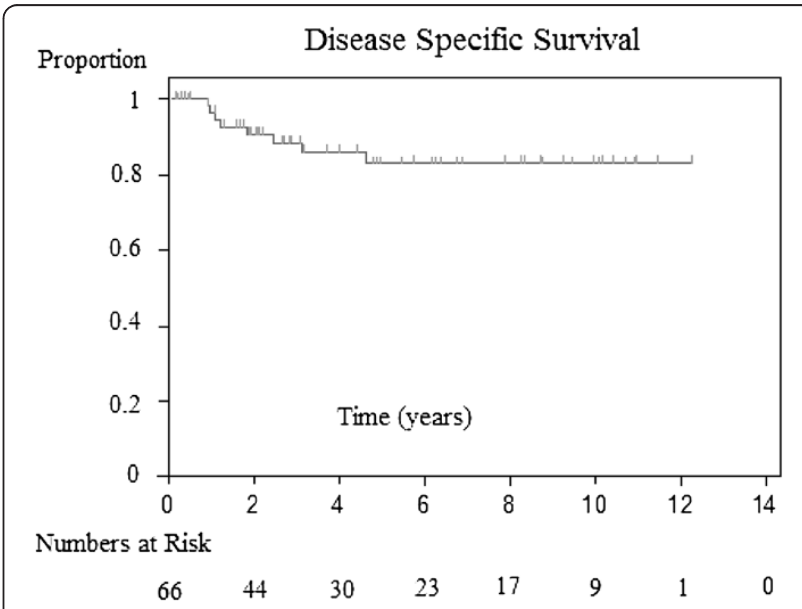

Figure 3 Comparison of Kaplan-Meier estimated overall survivals between patients with different extent of parotidectomy. 


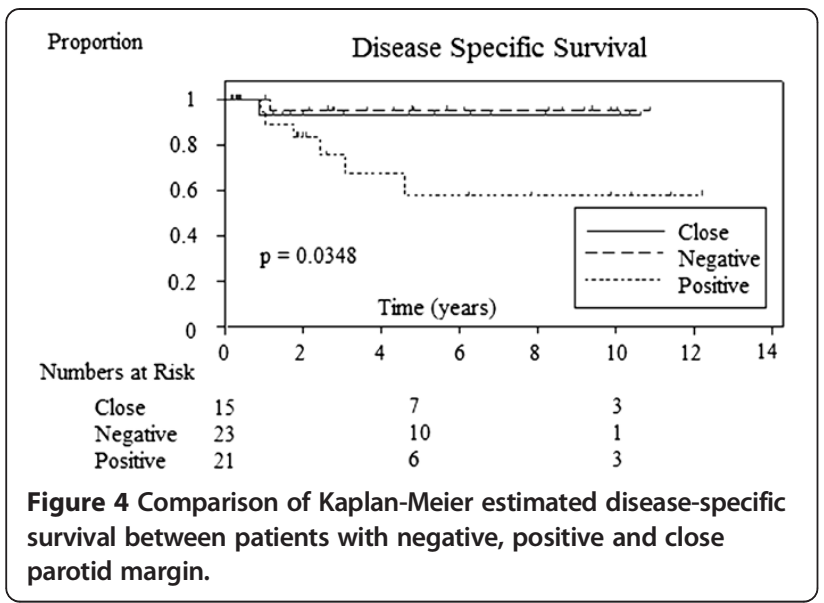

\section{Discussion}

Metastatic cSCC to the parotid gland is a relatively common clinical presentation faced by Australian head and neck surgeons and radiation oncologists. Unfortunately, there are no randomised control trials to guide treatment recommendations, and our current management guidelines are based on similar retrospective studies from other Australian institutions.

The survival analysis showed that this cohort had similar survival rates to other studies. Table 2 compares the results of our studies to other institutions. However, the two- and five-year disease-free survival rates of $91 \%$ and $83 \%$ respectively are slightly higher than other reported series [5,7-11]. This may be because all of our analyzed patients were treated with surgery with clearance of at least all macroscopic disease, and also radiotherapy to parotid and all but one to the ipsilateral neck. The other studies included patients treated with just radiotherapy or just surgery.

Table 2 Comparison to other similar studies

\begin{tabular}{|c|c|c|c|c|}
\hline Series & Duration & Number & $\begin{array}{l}\text { \% Treated } \\
\text { with surgery } \\
\text { and adjuvant } \\
\text { radiotherapy }\end{array}$ & $\begin{array}{l}\text { Survival at } \\
5 \text { years }\end{array}$ \\
\hline O'Brien et al. [5] & 1990-2002 & 87 & 86 & $63 \%$ DSS \\
\hline \multirow[t]{3}{*}{ Ch'ng et al. [7] } & 1990-2004 & 67 & 67 & $44 \%$ CSS \\
\hline & & & & $54 \%$ DSS \\
\hline & & & & $79 \%$ DFS \\
\hline Chua et al. [8] & 1980-1997 & 52 & 100 & $65 \%$ CSS \\
\hline Palme et al. [9] & 1987-1999 & 126 & 89 & $68 \%$ DSS \\
\hline Dona et al. [10] & $1983-2000$ & 74 & 100 & $72 \%$ CSS \\
\hline Veness et al. [11] & $1980-2000$ & 167 & 87 & $73 \%$ DFS \\
\hline \multirow[t]{2}{*}{$\begin{array}{l}\text { Goh et al. } \\
\text { (current study) }\end{array}$} & 1996-2006 & 66 & 100 & $72 \%$ OS \\
\hline & & & & $83 \%$ DSS \\
\hline
\end{tabular}

CSS, cause-specific survival; DFS, disease-free survival; DSS, disease-specific survival; OS, overall survival.
Analysis of prognostic variables showed that patients that underwent total parotidectomy had a significantly worse outcome than patients requiring superficial parotidectomy (superficial versus total; $P=0.0256$ ). This would seem logical as patients requiring total parotidectomy had more advanced locoregional disease. This study has also confirmed the adverse prognostic implication of positive margins on disease-free survival (Close/negative versus positive $P=0.0348$ ). The five-year disease-free survival of patients with negative parotid margins was $88 \%$ compared with $41 \%$ for patients with positive parotid margins. This once again highlights the importance of attempting to achieve clear surgical margins. The adverse effect of positive parotid margins in patients with metastatic cSCC has also been identified in other studies $[5,10]$. Careful preoperative planning with appropriate imaging such as CT and/or MRI scan is recommended when tumour extension outside the parotid gland is suspected. Patients can then be appropriately counseled about the possible need for adjacent soft tissue resection and arrangements for appropriate reconstruction can be made.

The significant effect of immune compromise in this group of patients has been validated in other studies [12-14]. These patients have significantly worse overall survival than immune-competent patients. Interestingly, when we compared disease-specific survival between these two patient populations no significant survival difference was found.

The role of elective neck dissection also remains controversial. Several Australian studies have demonstrated that approximately one third of patients with metastatic cSCC to the parotid gland with clinically negative necks will have occult metastases identified following neck dissection $[15,16]$. Selective neck dissection is a relatively straightforward procedure associated with relatively limited morbidity, particularly when combined with parotidectomy. We routinely perform elective supraomohyoid neck dissection in conjunction with parotidectomy. There are, as yet, no randomised control trials comparing adjuvant radiotherapy to elective neck dissection in the treatment of the clinically negative neck in this disease.

\section{Conclusions}

Cutaneous squamous cell carcinoma metastatic to the parotid is a challenging condition requiring multidisciplinary assessment and multimodality therapy. This retrospective review performed on 67 patients at St Vincent's Hospital, Sydney, between 1996 and 2006 confirmed the adverse prognostic implication of positive margins on disease-free survival. Immune compromise was not a significant factor in this small group. 


\section{Additional files}

Additional file 1: A table showing overall survival.

Additional file 2: A table showing disease-specific survival.

\section{Abbreviations}

CSCC: cutaneous squamous cell carcinoma; CT: computed tomography scan; DSS: disease-specific survival; Gy: gray; MRI: magnetic resonance imaging; NMSC: non-melanoma skin cancer; OS: overall survival; SD: standard deviation.

\section{Competing interests}

The authors have declared that they have no competing interests.

\section{Acknowledgements}

We would like to acknowledge the clinicians who attend out head and neck multidisciplinary meeting including Dr Stephen Cooper, Dr Raj Jagavkar, Dr Michael Jensen, Dr Chris Hughes, Dr Richard Gallagher, Dr David Dalley without whom this publication would not be possible. We would also like to thank Kate Morrow for her assistance with the manuscript.

\section{Author details}

${ }^{1}$ Faculty of Medicine, University of New South Wales, Botany Street, Sydney, NSW 2052, Australia. Department of Head and Neck Surgery, St Vincent's Hospital, 390 Victoria Street, Darlinghurst, NSW 2010, Australia. ${ }^{3}$ Genesis Cancer Care, St Vincent's Clinic, 438 Victoria Street, Darlinghurst, NSW 2010, Australia. ${ }^{4}$ Radiation Oncology, Mater Hospital, 25 Rocklands Rd, Crows Nest, NSW 2065, Australia.

\section{Authors' contributions}

RG collected and analysed the data and wrote the manuscript. RB refined the study design and corrected the manuscript. GF conceived the study, created the study design, corrected and submitted the manuscript. All authors have read and approved the final manuscript.

Received: 22 January 2012 Accepted: 25 June 2012

Published: 25 June 2012

\section{References}

1. Rogers HW, Weinstock MA, Harris AR, Hinckley MR, Feldman SR, Fleischer $A B$, Coldiron BM: Incidence estimate of nonmelanoma skin cancer in the United States, 2006. Arch Dermatol 2010, 146:283-287.

2. Staples MP, Elwood M, Burton RC, Williams JL, Marks R, Giles GG: Nonmelanoma skin cancer in Australia: the 2002 national survey and trends since 1985. Med J Aust 2006, 184:6-10.

3. Australian Institute of Health and Welfare (AlHW) \& Australasian Association of Cancer Registries (AACR): Australian cancer incidence and mortality workbooks (ACIM). Canberra: AlHW; 2010. Retrieved from [www.aihw.gov.au/ cancer/data/acim_books/index.cfm] on 13 October 2011.

4. Kwa RE, Campana K, Moy RL: Biology of cutaneous squamous cell carcinoma. J Am Acad Dermatol 1992, 26:1-26.

5. O'Brien CJ, McNeil EB, McMahon JD, Pathak I, Lauer CS, Jackson MA: Significance of clinical stage, extent of surgery, and pathologic findings in metastatic cutaneous squamous carcinoma of the parotid gland. Head Neck 2002, 24:417-422.

6. Robbins KT, Shaha AR, Medina JE, Califano JA, Wolf GT, Ferlito A, Som PM, Day TA, Committee for Neck Dissection Classification, American Head and Neck Society: Consensus statement on the classification and terminology of neck dissection. Arch Otolaryngol Head Neck Surg. 2008, 134:536-538.

7. Ch'ng S, Maitra A, Lea R, Brasch H, Tan ST: Parotid metastasis - An independent prognostic factor for head and neck cutaneous squamous cell carcinoma. Journal of Plastic, Reconstructive \& Aesthetic Surgery 2006, 59:1288-129.

8. Chua MS, Veness MJ, Morgan G, Shakespeare T, Hehir A, Gebski V, Cakir B, Tiver KW: Parotid lymph-node metastases from cutaneous squamous-cell carcinomas: treatment outcome and prognostic factors following surgery and adjuvant radiotherapy. Australas Radiol 2002, 46:174-179.

9. Palme CE, O'Brien CJ, Veness MJ, McNeil EB, Bron LP, Morgan GJ: Extent of parotid disease influences outcome in patients with metastatic cutaneous squamous cell carcinoma. Archives of otolaryngology- head \& neck surgery 2003, 129:750-753.

10. Dona E, Veness MJ, Cakir B, Morgan GJ: Metastatic cutaneous squamous cell carcinoma to the parotid: the role of surgery and adjuvant radiotherapy to achieve best outcome. ANZ J Surg 2003, 73:692-696.

11. Veness MJ, Palme CE, Smith M, Cakir B, Morgan GJ, Kalnins I: Cutaneous head and neck squamous cell carcinoma metastatic to cervical lymph nodes (nonparotid): a better outcome with surgery and adjuvant radiotherapy. Laryngoscope 2003, 113:1827-1833.

12. Veness MJ, Morgan GJ, Palme CE, Gebski V: Surgery and adjuvant radiotherapy in patients with cutaneous head and neck squamous cell carcinoma metastatic to lymph nodes: combined treatment should be considered best practice. Laryngoscope 2005, 115:870-875.

13. Martinez JC, Otley CC, Stasko T, Euvrard S, Brown C, Schanbacher CF, Weaver AL: Defining the clinical course of metastatic skin cancer in organ transplant recipients: a multicenter collaborative study. Arch Dermatol 2003, 139:301-306.

14. Veness MJ, Quinn DI, Ong CS, Keogh AM, Macdonald PS, Cooper SG, Morgan GW: Aggressive cutaneous malignancies following cardiothoracic transplantation: the Australian experience. Cancer 1999, 85:1758-1764.

15. O'Brien CJ, McNeil EB, McMahon JD, Pathak I, Lauer CS: Incidence of cervical node involvement in metastatic cutaneous malignancy involving the parotid gland. Head Neck 2001, 73:744-748.

16. Bova R, Saylor A, Coman WB: Parotidectomy: review of treatment and outcomes. ANZ J Surg 2004, 74:563-568.

doi:10.1186/1477-7819-10-117

Cite this article as: Goh et al:: Cutaneous squamous cell carcinoma metastatic to parotid - analysis of prognostic factors and treatment outcome. World Journal of Surgical Oncology 2012 10:117.

\section{Submit your next manuscript to BioMed Central and take full advantage of:}

- Convenient online submission

- Thorough peer review

- No space constraints or color figure charges

- Immediate publication on acceptance

- Inclusion in PubMed, CAS, Scopus and Google Scholar

- Research which is freely available for redistribution

Submit your manuscript at www.biomedcentral.com/submit
C Biomed Central 